\title{
KONSEPTUALISASI PROFETIK
}

\author{
Nur Hanafi \\ Email: ma9936488@gmail.com
}

\begin{abstract}
Scientific disruption today, complex problems related to integrative education through prophetic education. The phenomenon of difficulty that becomes an important point we can make the lens to see the current educational approach. Education has not revisited religious prophetic values to be delivered to the public sphere. Given this, we can not reconcile the dichotomy of general education and religious education in the formal law. Education Indonesia should display human figures in the role model or model that must be imitated in accordance with the output of character education itself. But it aims to describe the implementation of education from various kinds of integration between educational institutions, family and society and based on monthly values. Also raises research questions how the values of prophetic education ?. To answer this research question, researchers collect data through documentation method. Then after the data collected, analyzed analysis and critical analysis. This research produces one of the solutions of integrative learning concepts with the standards and figures of a truly powerful and irrefutable model that is the Prophet Muhammad and returns to the activities, feelings, thoughts in interpreting the Qur'an and Sunnah.
\end{abstract}

Keywords: Meaning, definition, historical

\section{Pendahuluan}

Permasalahan pendidikan sudah lama dan sering menjadi pokok utama perdiskusian masyarakat Indonesia, khususnya para pengamat dan pakar-pakar education. Diskusi-diskusi tersebut telah menghasilkan berbagai definisi tentang hakekat, peranan serta pentingnya pendidikan. Sehingga ini untuk mendapatkan perhatian dari pemerintah maupun masyarakat yang peduli terhadap pendidikan.

Sejauh perkembangannya selama ini, baik secara konseptual maupun teknisnya di lapangan, pendidikan telah mengalami beberapa fase perubahan. Hal itu disebabkan karena pendidikan selalu mencoba melahirkan konsep-konsep baru dalam mengatasi berbagai persoalan yang muncul di dalamnya. Namun tidak bisa dipungkiri bahwa pendidikan di Indonesia justru terjebak ke dalam sebuah cara pandang dan ideologi yang sebagian besar mengadopsi (mencontoh atau memodelkan) dari Barat. Hal ini berdampak akan pendidikan yang semakin kehilangan jati dirinya. 
Kebebasan di dalam bidang pendidikan, yang berakibat kepada pendidikan yang dikomersilkan, semakin menjadikan masyarakat sulit untuk mengakses pendidikan. Dengan demikian maka peradaban menjadi terancam, karena manusia sudah tidak lagi diposisikan sebagai model makhluk paling utama, tetapi manusia disamakan dengan mesin dan hewan.

Oleh sebab itu, dibutuhkan sebuah sintesis yang paling memungkinkan dalam menyelesaikan beberapa persoalan tersebut. Dibutuhkan konsep pendidikan yang bukan hanya bersifat akomodatif, namun juga harus berangkat dari sebuah paradigma pendidikan yang berkomitmen terhadap kebenaran. Untuk itulah upaya pencarian alternatif dalam bentuk konsep yang selanjutnya akan dikembangkan secara baik dan benar menjadi sebuah keniscayaan untuk dilakukan. Konsep pendidikan yang didesain berdasarkan kebutuhan mendasar manusia. Namun dengan tetap tidak terlepas dari nilai-nilai dasar sebagai pondasi utamanya Islam. ${ }^{1}$

\section{Makna Profetik}

Ilmu Sosial Profetik atau biasa disingkat adalah merupakan salah satu gagasan penting dari sosila yakni professor kuntowijoyo. Menurutnya ilmu sosial tidak boleh berbangga diri dalam usaha untuk menjelaskan atau memahami realitas (kenyataan yang ada) dan kemudian memaafkannya begitu saja tetapi lebih dari itu, ilmu sosial harus juga mampu menjalankan tugas transformasi (perubahan yang dinamis) menuju cita-cita yang diidealkan masyarakatnya. Menurut Kuntowijoyo kemudian merumuskan tiga nilai dasar sebagai pijakan ilmu sosial profetik, yaitu: humanisasi, liberasi dan transendensi. Ide ini kini mulai banyak dikaji. Di bidang

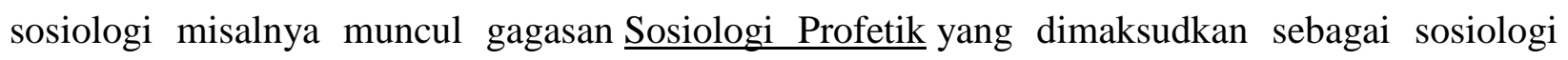
berparadigma ilmu social profetik.

Pemaknaaan profetik berawal dari bahasa inggris prophet (nabi) sedangkan prophetic bermakna (kenabian). ${ }^{2}$ Yaitu sifat nabi yang mempunyai ciri sebagai manusia yang ideal secara spiritual-individual, tetapi juga menjadi pelopor perubahan, membimbing masyarakat ke arah perbaikan dan melakukan perjuangan tanpa henti melawan penindasan. Dalam sejarah, Nabi

\footnotetext{
${ }^{1}$ Muhamad Khoirul Umam, "RECONSTRUCTION OF INTEGRATIVE ISLAMIC EDUCATION IN THE TRANSFORMATIVE PROFETICAL EDUCATION FRAMEWORK," in PROCEEDINGS 2st Annual Conference for Muslim Scholars (AnCoMS) Kopertais Wilayah IV Surabaya., ed. Abdul Muhid et al. (Surabaya: Kopertais4 Press, 2018), 511-20, https://scholar.google.co.id/scholar?oi=bibs\&cluster=9833530191946745276\&btnI=1\&hl=id.

${ }^{2}$ M. Dagum, Kamus Besar Ilmu Pengetahuan, (Jakarta: Lembaga Pengkajian Nusantara, 2006), 897.
} 
Ibrahim melawan Raja Namrud, Nabi Musa melawan Fir'aun, Nabi Muhammad yang membimbing kaum miskin dan budak belia melawan setiap penindasan dan ketidakadilan, mempunyai tujuan untuk menuju kearah pembebasan. ${ }^{3}$ Menurut Ali Syari'ati dalam Hilmy para nabi tidak hanya mengajarkan dzikir dan do'a tetapi mereka juga datang dengan suatu ideologi pembebasan. ${ }^{4}$ Dalam Oxford Dictionary, prophetic merupakan:

Of pertaining or paper to a prophet or prophecy: having the character or function of a prophet, characterized by containing or of the nature of prophecypredictive.

Yang diterjemahkan:

Tentang atau kertas untuk seorang nabi atau nubuat: memiliki karakter atau fungsi seorang nabi, yang dicirikan oleh mengandung atau sifat nubuatan yang bersifat nabati

\section{Definitif Profetik}

Kata prophetic yang merupakan berawal dari bahasa inggris itu berasal dari bahasa yunani prophetes yang memiliki arti sebuah kata benda untuk menyebut seseorang berbicara awal atau seseorang yang memproklamasikan diri dan dapat berarti juga seseorang yang berbicara masa depan. ${ }^{5}$ Jadi pemaknaan profetik memiliki sifat atau kecirian seperti nabi atau bersifat prediktif, memperkirakan, yang diartikan sebagai kenabian.

Selanjutnya kenabian terkandung makna dalam segala hal ihwal yang berhubungan dengan seseorang yang telah memperoleh potensi kenabian. ${ }^{6}$ Potensi kenabian dapat menginternalisasi dalam diri setelah melakukan proses pendidikan dengan langkah-langkah pengelolaan (manajemen) jiwa serta raga yang didahului oleh pendasaran filosofi yang disandarkan pada nilai-nilai kenabaian dalam Al Qur'an, Sunnah, dan Ijtihad dengan berbagai upaya pemikiran yang mencerminkan dan prediksi sampai kepada penelitian empiris. ${ }^{7}$

\section{Historisitas Profetik}

\footnotetext{
${ }^{3}$ Muhammad Basyam Rusydi Az-Zain, Sekolah Para Nabi 1 \& 2. (Yogyakarta: Pustaka Marwa, 2007),

4 Ali Shari'ati, Humanisme: Antara Islam dan Mazhab Barat, terj. Husein Anis al- Habshi, (Bandung: Pustaka Indah, 1996), 119.

${ }^{5}$ Moh. Roqib, Filsafat Pendidikan Profetik: Pendidikan Islam integrative dalam Persfektif Kenabian Muhamad,(Purwokerto: An-najah Press, 2016), 26-37

${ }^{6}$ Hamdani Bakran Adz-Dzakiey, Prophetic Psychology: Psikologi Kenabian Menghidupkan Potensi dan Kepribadian Kenabian dalam diri, (Yogyakarta: Pustaka Al Furqon, 2007), 44.

${ }^{7}$ Umam, "RECONSTRUCTION OF INTEGRATIVE ISLAMIC EDUCATION IN THE TRANSFORMATIVE PROFETICAL EDUCATION FRAMEWORK."
} 
Secara historisas pengetahuan serta pemikiran profetik diperbincangkan sangat intensif oleh ibnu arabi (1165-1241) dan Surahwadi (1155-1191) yang secara garis besar mengkritik pengetahuan seerta pemikiran yunani serta menawarkan profetik yang intinya adalah dialektika manusia, alam dan Tuhan dikembangkan untuk mendapatkan produk pemikiran baru sebagai alternatif pemikiran barat yang dinyatakan gagal.

Kemudian di Indonesia lebih lanjut oleh Moh Roqib dalam pemikiran profetiknya, memunculkan gagasan yang mengarah kepada pendidikan dan menjadi sebuah teori baru pendidikan profetik, yang terilhami dari pemikiran kuntowijoyo yang menjadi dasar profetik (humanisasi, liberasi, dan transendensi) yang dijadikan dalam pengembangan pendidikan profetiknya. Tiga pilar dasar profetik itu menjadi keharusan berdialektika dengan budaya local agar tetap kokoh karena tidak berhadapan dengan budaya setempat selama budaya tersebut tetap dalam bingkai akhlakulkarimah atau etika yang baik. ${ }^{8}$

Budaya sebagai landasan gerak langkah perilaku individu ataupun kelompok sosial harus dibangun dengan mempertahankan yang positif dan mengambil secara kreatif hal baru yang lebih baik dan bermanfaat dalam kehidupan. ${ }^{9}$ Disamping itu pula perlu didasari oleh cara pandang nilai-nilai kenabian yakni: a). dasar tauhid menjadikan ilmu sosial, kebudayaan, dan ilmu pengetahuan dan teknologi tidak terpisahkan dengan filsafat dan tasawuf, b). dasar nabi (prophet) sebagai sosok pandangan model uswatun hasanah serta seorang manusia yang diberi kemampuan oleh Tuhannya, c). dasar ilmu sebagai medan sentuh pemikiran akal manuisa yang disandarkan kepada Allah. ${ }^{10}$

\section{Simpulan}

Potensi kenabian dapat menginternalisasi dalam diri setelah melakukan proses pendidikan dengan langkah-langkah pengelolaan (manajemen) jiwa serta raga yang didahului oleh pendasaran filosofi yang disandarkan pada nilai-nilai kenabaian dalam Al Qur'an, Sunnah, dan Ijtihad.

\footnotetext{
${ }^{8}$ Umam.

${ }^{9}$ Moh. Roqib, Filsafat Pendidikan Profetik: Pendidikan Islam integrative dalam Persfektif Kenabian Muhamad, (Purwokerto: An-najah Press, 2016), 34

${ }^{10}$ Umam, "RECONSTRUCTION OF INTEGRATIVE ISLAMIC EDUCATION IN THE TRANSFORMATIVE PROFETICAL EDUCATION FRAMEWORK."
} 
Tiga pilar dasar profetik itu menjadi keharusan berdialektika dengan budaya local agar tetap kokoh karena tidak berhadapan dengan budaya setempat selama budaya tersebut tetap dalam bingkai akhlakulkarimah atau etika yang baik.

Dasar tauhid menjadikan ilmu sosial, kebudayaan, dan ilmu pengetahuan dan teknologi tidak terpisahkan dengan filsafat dan tasawuf. Dasar nabi (prophet) sebagai sosok pandangan model uswatun hasanah serta seorang manusia yang diberi kemampuan oleh Tuhannya. Dasar ilmu sebagai medan sentuh pemikiran akal manuisa yang disandarkan kepada Allah.

\section{Daftar Rujukan}

Muhamad Khoirul Umam, "RECONSTRUCTION OF INTEGRATIVE ISLAMIC EDUCATION IN THE TRANSFORMATIVE PROFETICAL EDUCATION FRAMEWORK," in PROCEEDINGS 2st Annual Conference for Muslim Scholars (AnCoMS) Kopertais Wilayah IV Surabaya., ed. Abdul Muhid et al. (Surabaya: Kopertais4 Press, 2018), $511-20$ https://scholar.google.co.id/scholar?oi=bibs\&cluster=9833530191946745276\&btnI=1\&hl= id.

M. Dagum, Kamus Besar Ilmu Pengetahuan, (Jakarta: Lembaga Pengkajian Nusantara, 2006), 897.

Muhammad Basyam Rusydi Az-Zain, Sekolah Para Nabi 1 \& 2. (Yogyakarta: Pustaka Marwa, 2007),

Ali Shari'ati, Humanisme: Antara Islam dan Mazhab Barat, terj. Husein Anis al- Habshi, (Bandung: Pustaka Indah, 1996), 119.

Moh. Roqib, Filsafat Pendidikan Profetik: Pendidikan Islam integrative dalam Persfektif Kenabian Muhamad,(Purwokerto: An-najah Press, 2016), 26-37

Hamdani Bakran Adz-Dzakiey, Prophetic Psychology: Psikologi Kenabian Menghidupkan Potensi dan Kepribadian Kenabian dalam diri, (Yogyakarta: Pustaka Al Furqon, 2007), 44.

Moh. Roqib, Filsafat Pendidikan Profetik: Pendidikan Islam integrative dalam Persfektif Kenabian Muhamad, (Purwokerto: An-najah Press, 2016), 34

Umam, M. K. (2017, May). Strategi Alternatif Memajukan Lembaga Pendidikan Islam di Pedesaan Berbasis Sekolah Excellent Perspektif Kompetitif Kotemporer. In PROCEEDINGS: Annual Conference for Muslim Scholars (No. Seri 2, pp. 769-776)

Umam, M. K. (2018, February). Paradigma Pendidikan Profetik dalam Pendekatan Pembelajaran Tematik di Madrasah Ibtidaiyah. In PROCEEDING: The 3rd Annual International Conference on Islamic Education (Vol. 3, No. 1, pp. 120-132)

Umam, M. K. (2018, April). Reconstruction of Integrative Islamic Education in The Transformative Profetical Education Framework. In PROCEEDINGS: Annual Conference for Muslim Scholars (No. Series 1, pp. 511-520). 
Umam, M. K. (2017). ANALISIS LINGKUNGAN STRATEGIK DALAM CORAK PENYELENGGARAAN PENDIDIKAN ISLAM. Jurnal al Hikmah, 5(1), 1-8. 